\title{
Pattern of Cardiovascular Diseases as Seen in an Out-Patient Cardiac Clinic in Ghana
}

\author{
Isaac Kofi Owusu1,2*, Emmanuel Acheamfour-Akowuah ${ }^{2}$ \\ ${ }^{1}$ Department of Medicine, School of Medical Sciences, College of Health Sciences, Kwame, Nkrumah University of Science and \\ Technology, Kumasi, Ghana \\ ${ }^{2}$ Directorate of Medicine, Komfo Anokye Teaching Hospital, Kumasi, Ghana \\ Email: ^ikeowusu@yahoo.com
}

How to cite this paper: Owusu, I.K. and Acheamfuor-Akowuah, E. (2018) Pattern of Cardiovascular Diseases as Seen in an Out-Patient Cardiac Clinic in Ghana. World Journal of Cardiovascular Diseases, 8, 70-84.

https://doi.org/10.4236/wjcd.2018.81008

Received: November 20, 2017

Accepted: January 27, 2018

Published: January 30, 2018

Copyright (c) 2018 by authors and Scientific Research Publishing Inc. This work is licensed under the Creative Commons Attribution International License (CC BY 4.0).

http://creativecommons.org/licenses/by/4.0/

\begin{abstract}
Cardiovascular diseases (CVDs) are increasingly emerging as a major health problem in sub-Saharan Africa, but information on the epidemiology, clinical characteristics and spectrum of the diseases are scanty. Epidemiological data regarding the incidence and prevalence of CVDs in different geographical regions are essential to our understanding of global distribution and evolution of CVDs. We conducted a retrospective observational study to determine the prevalence and spectrum of cardiovascular diseases in patients seen at the out-patient cardiac clinic of the Directorate of Medicine, Komfo Anokye Teaching Hospital (KATH), Kumasi, Ghana. Medical records of 432 patients selected from the cardiac clinic using simple random sampling. The medical history, including the socio-demographic information, was examined. The results of the patients' laboratory tests, chest X-ray, electrocardiography, M-mode and two-dimensional echocardiography with Doppler and colour flow imaging of the patients were also examined. The patients were aged between 13 - 97 years with the mean age ( \pm standard deviation) of $55.35( \pm 19)$ years. There were more females $(53 \% ; n=229)$ than males $(47 \% ; n=203)$. The main cardiovascular diseases seen included: hypertensive heart disease (35.6\%; $\mathrm{n}=154)$, valvular heart disease $(19.7 \% ; \mathrm{n}=85)$, cardiomyopathies $(18.5 \% ; \mathrm{n}=80)$, arrhythmias $(6.3 \% ; \mathrm{n}=27)$ and coronary artery disease $(4.2 \% ; \mathrm{n}=18)$. The most common causes of valvular heart disease, cardiomyopathies and arrhythmias were rheumatic heart disease, dilated cardiomyopathy and complete heart block respectively. In conclusion, our study has shown that hypertensive heart disease, rheumatic heart disease and cardiomyopathies were the main cardiovascular diseases, seen in $73.8 \%$ of the patients in this study.
\end{abstract}




\section{Keywords}

Cardiovascular Diseases, Hypertensive Heart Disease, Valvular Heart Disease, Ghana, Sub-Saharan Africa

\section{Introduction}

Cardiovascular diseases (CVDs) constitute the greatest burden of morbidity and mortality worldwide and they are set to overtake infectious diseases in the developing world as the most common cause of mortality [1] [2] [3] [4]. Categorization of the pathologies underlying CVDs is complex since the primary disease process is often interdependent. Despite wide heterogeneity in the prevalence of CVDs across different regions, CVDs have emerged as the leading cause of mortality in every region of the world with the sole exception of sub-Saharan Africa, where infectious diseases are still the leading cause [3] [5] of death. For a very long period, CVDs were considered as negligible in sub-Saharan Africa, especially compared with other public health issues such as infectious diseases. However, the modern epidemiologic transition associated with greater urbanisation, socioeconomic development, and modernisation of dietary patterns and lifestyles has contributed hugely to an increase in the burden of CVDs [6]. In addition, the increasing longevity in Africa has provided longer periods of exposure to the risk factors of CVDs, resulting in a greater probability of clinically manifest CVDs events [7].

Evidence from several studies suggests that CVDs are gaining ground in sub-Saharan Africa, against a background of highly prevalent infectious diseases, some of which have chronic manifestations, which are still contributing to a significant proportion of morbidity and mortality on the sub-region [8]. Sub-Saharan African countries therefore face a double burden of diseases, as the sub-region struggles to cope with the burden of communicable diseases such as HIV/AIDS, tuberculosis and malaria-the "unfinished agenda", as well as the burden of non-communicable diseases especially cardiovascular diseases-the "emerging agenda" [7] [9]. This implies that while infections and infestations are still a major health problem in African countries, CVDs have also become a huge health challenge, resulting in inadequate attention to both categories of disease [7] [9].

Despite the fact that, CVDs epidemic has receded in many developed countries in the past decades, sub-Saharan Africa and other developing countries have experienced an increase in the prevalence of CVDs and over $80 \%$ of global morbidity and mortality from CVDs now occur in these countries [4] [5] [10]. Considering the medical and socioeconomic consequences, the increase in the burden of CVDs will be appalling for the sub-Saharan African countries, whose healthcare systems are already struggling to cope with epidemics of infectious diseases, perinatal and maternal diseases. In addition, the economic impact in 
regard to loss of productive years of life and the need to divert scarce resources to tertiary care will be greatly substantial.

The prevalence and pattern of CVDs vary both within and between regions, and countries depending on factors such as genetic predisposition and environmental factors such as dietary habits, physical activity and the burden of infectious diseases as well as availability of healthcare systems [9] [10] [11] [12]. It is largely documented that hypertensive heart disease, rheumatic heart disease and cardiomyopathies are the major CVDs in sub-Saharan Africa [9] [11] [12] [13] [14], which is at variance with findings from the Western world where CVDs are largely due to coronary artery disease [15]. Furthermore, CVDs in sub-Saharan Africa are diseases of relatively younger people, with a high early mortality rate.

In a prospective study among patients in Kenya, clinical evidence of CVDs was present in $40 \%$ of the patients examined: over $52 \%$ of them were hypertensives and had arrhythmias, and $49 \%$ had congestive heart failure [6]. In a retrospective study conducted in the Cameroun, comprising 312 adult patients with CVDs, $38.5 \%$ of them were hypertensives, $25.6 \%$ had rheumatic heart disease and $22.5 \%$ had cardiomyopathies [12]. Recent studies from Nigeria reported hypertensive heart disease, cardiomyopathies and valvular heart disease as the most frequent echocardiographic diagnosis among patients presenting with CVDs [16] [17]. A Ghanaian study done over 10 years ago reported that, hypertensive heart disease (18.7\%), dilated cardiomyopathy (17.4\%), congenital heart disease $(14.5 \%)$ and coronary artery disease $(11.3 \%)$ were the main causes of CVDs.

Ghana shares the same burden of CVDs with the other sub-Saharan African countries, which tend to present with severe disease and grave complications [9] [18] [19]. The need for availability of adequate data on CVDs cannot be over-emphasized. Knowledge of the current profile of CVDs in our setting is essential for the development of appropriate healthcare policies, strategies and interventions to prevent and treat CVDs. This study was therefore designed to determine the prevalence and spectrum of CVDs in patients seen at the out-patient cardiac clinic of the Komfo Anokye Teaching Hospital (KATH), Kumasi, Ghana.

\section{Methods}

This was retrospective and descriptive study carried out at the cardiac clinic, Directorate of Medicine, KATH, Kumasi, Ghana. Ethical approval was obtained from the institutional ethical committee.

Medical records of four hundred and thirty-two (432) patients were selected from the cardiac clinic, using simple random sampling. Standard questionnaires were used to collect the data. The medical history; including the socio-demographic information of the patients were obtained. The presence of hypertension, use of anti-hypertensive drugs, diabetes mellitus, oral hypoglycaemic agents and insulin use, alcohol ingestion and smoking of cigarettes were recorded. Previous history of hypertension, rheumatic fever/rheumatic heart disease, coronary artery 
disease, diabetes mellitus, and angina or myocardial infarction was also obtained. The results of the patients' laboratory investigations, chest X-ray, electrocardiography, and echocardiography were obtained. The echocardiographic data included; M-mode, 2-dimensional, spectral Doppler, colour flow imaging, characteristics of valvular apparatus and left ventricular systolic and diastolic function.

Hypertension was diagnosed as the presence of a persistent elevated systolic blood pressure $\geq 140 \mathrm{mmHg}$ and/or diastolic blood pressure $\geq 90 \mathrm{mmHg}$ in patients aged 18 years and above or presence of hypertensive retinopathy and/or the use of antihypertensive drugs and/or past medical history of hypertension drugs [20].

Coronary artery disease was diagnosed based on the combination of documented history of chest pain, ECG abnormalities, raised serum troponins, and segmental wall motion abnormalities.

Left ventricular systolic dysfunction was defined as left ventricular ejection fraction $(\mathrm{EF})<50 \%$.

Left ventricular diastolic dysfunction was defined as E/A ratio $<1$ or E/A ratio $>2$, DT $>220 \mathrm{~ms}$ or DT $<160 \mathrm{~ms}$, IVRT $>100 \mathrm{~m}$ or IVRT $<70 \mathrm{~ms}$.

Hypertensive heart disease was diagnosed as presence of hypertension and any one or combination of the following abnormalities: left ventricular diastolic dysfunction and/or left ventricular systolic dysfunction (ejection fraction < $50 \%$ ), left ventricular hypertrophy, and dilated left atium; left atrial diameter in women $\geq 3.8 \mathrm{~cm}$ and in men $\geq 4.0 \mathrm{~cm}$.

Diagnosis of rheumatic heart disease was made using World Heart Federation criteria [21].

Cor-pulmonale was said to be present when there was dilated and hypertrophied right ventricle and Doppler evidence of pulmonary hypertension [22].

Dilated cardiomyopathy (DCM) was diagnosed when there were dilated cardiac chambers with normal or reduced wall thickness as well as left ventricular systolic dysfunction with ejection fraction $<40 \%$ [23].

Pulmonary hypertension was defined as right ventricular systolic pressure $\geq$ $35 \mathrm{mmHg}$ in the absence of pulmonary stenosis.

\section{Statistical design and analysis}

Data from the questionnaires were entered into a Microsoft Excel (2010) sheet. Data were cleaned, edited and exported into SPSS for Windows version 12.0 for statistical analysis.

Descriptive analysis of baseline parameters was provided. Frequencies and percentages were calculated for categorical variables. For continuous data, measure of central tendency using mean was calculated, and measure of spread using standard deviation and range were also calculated.

\section{Results}

Data from a total of four hundred and thirty-two (432) patients were studied. 
The baseline socio-demographic characteristics of the patients are represented in Table 1 and Figure 1. There were 203 (47\%) males and 229 (53\%) females. The age of the patients ranged from 13 years to 97 years with a mean \pm (standard deviation) of $55.35 \pm$ (19.01) years. About $70 \%$ of the patients were aged 50 years and over. Eighty-five percent (85.0\%) of them were Christians, $12.5 \%$ were Moslems, $1.6 \%$ were pagans and $0.9 \%$ had no religious affiliation. About thirty-two percent (32.2\%) were unemployed, $16.2 \%$ were farmers, and $20.4 \%$ were traders.

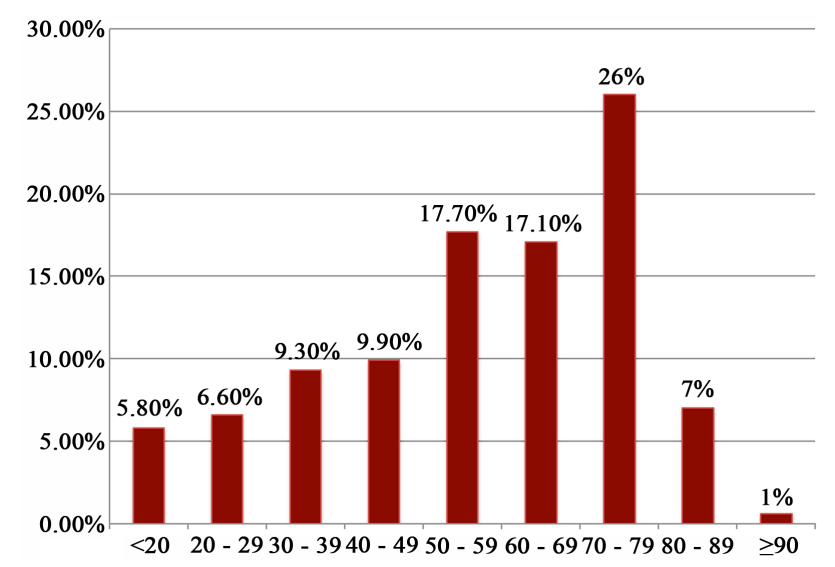

Figure 1. Graph showing age distribution of patients.

Table 1. Clinical and socio-demographic characteristics of the study patients.

\begin{tabular}{|c|c|c|}
\hline Variable & Frequency & Percentage \\
\hline \multicolumn{3}{|l|}{ Sex } \\
\hline Male & 203 & 47 \\
\hline Female & 229 & 53 \\
\hline \multicolumn{3}{|l|}{ Religion } \\
\hline Christian & 367 & 85.0 \\
\hline Moslem & 54 & 12.5 \\
\hline Pagan & 7 & 1.6 \\
\hline Others & 4 & 0.9 \\
\hline \multicolumn{3}{|l|}{ Marital status } \\
\hline Married & 279 & 64.6 \\
\hline Single & 76 & 17.6 \\
\hline Divorced & 23 & 5.3 \\
\hline Widow & 45 & 10.4 \\
\hline Widower & 9 & 2.1 \\
\hline \multicolumn{3}{|l|}{ Occupation } \\
\hline Traders & 88 & 20.4 \\
\hline Farmers & 70 & 16.2 \\
\hline Civil servants & 49 & 11.3 \\
\hline Artisans & 27 & 6.3 \\
\hline Students & 25 & 5.8 \\
\hline Unemployed & 139 & 32.2 \\
\hline Others & 34 & 7.9 \\
\hline
\end{tabular}


Patterns of Cardiovascular Disease observed in the Patients.

Table 2 and Table 3 show the patterns and the specific cardiovascular disorders observed in the patients. Overall, the most important cardiovascular disease aetiologies were hypertensive heart disease $(n=154 ; 35.6 \%)$, which was followed by valvular heart disease $(n=85 ; 19.7 \%)$, and cardiomyopathies $(n=80$; $18.5 \%)$. Arrhythmias $(n=27 ; 6.3 \%)$, coronary artery disease $(n=18 ; 4.2 \%)$ and congenital heart disease $(n=15 ; 3.5 \%)$ were other common cardiovascular disorders. Rheumatic heart disease, dilated cardiomyopathy and complete heart block were the major causes of valvular heart disease, cardiomyopathies and arrhythmias respectively. Hypertensive heart disease, valvular heart disease and arrhythmias were commoner in females while cardiomyopathy was commoner in males.

Table 4 shows the distribution by age and disease category. The peak incidence of cardiovascular disease occurred in the age category of 70 - 79 (26\%). The major cardiovascular disorders in subjects aged less than 30 years were rheumatic heart disease $(n=29)$, congenital heart disease $(n=7)$ and infective endocarditis $(n=4)$. Cardiomyopathy $(n=6)$ and arrhythmia $(n=4)$. Hypertensive heart disease and coronary artery disease were not recorded in patients aged less than 30. Interestingly, coronary artery disease was observed only between fourth and seventh decades.

Table 5 shows the distributions of associated medical conditions in the study.

Table 2. Cardiovascular disease patterns observed in the study subjects.

\begin{tabular}{|c|c|c|c|c|c|c|}
\hline \multirow{2}{*}{ Cardiovascular diseases } & \multicolumn{2}{|l|}{ Males } & \multicolumn{2}{|c|}{ Females } & \multicolumn{2}{|c|}{ Total } \\
\hline & Frequency & $\%$ & Frequency & $\%$ & Frequency & $\%$ \\
\hline Hypertensive Heart Disease & 75 & 37 & 79 & 34.5 & 154 & 35.6 \\
\hline Valvular Heart Disease & 29 & 14.3 & 56 & 24.5 & 85 & 19.7 \\
\hline Cardiomyopathies & 42 & 20.7 & 38 & 16.6 & 80 & 18.5 \\
\hline Arrhythmias & 9 & 4.4 & 18 & 7.9 & 27 & 6.3 \\
\hline Coronary Artery Disease & 14 & 6.9 & 4 & 1.7 & 18 & 4.2 \\
\hline Congenital Heart Disease & 7 & 3.4 & 8 & 3.5 & 15 & 3.5 \\
\hline Veno-Thromboembolism & 7 & 3.4 & 4 & 1.7 & 11 & 2.5 \\
\hline Pulmonary Hypertension & 3 & 1.5 & 5 & 2.2 & 8 & 1.9 \\
\hline Infective Endocarditis & 2 & 1 & 2 & 0.9 & 4 & 0.9 \\
\hline Sickle Cell Heart Disease & 1 & 0.5 & 3 & 1.3 & 4 & 0.9 \\
\hline Thyroid Heart Disease & 0 & 0 & 3 & 1.3 & 3 & 0.7 \\
\hline Pericardial Diseases & 2 & 1 & 1 & 0.4 & 3 & 0.7 \\
\hline Cor-pulmonale & 2 & 1 & 1 & 0.4 & 3 & 0.7 \\
\hline Others & 10 & 4.9 & 7 & 3.1 & 17 & 3.9 \\
\hline
\end{tabular}


Table 3. Specific cardiovascular diseases observed in the patients.

\begin{tabular}{|c|c|c|}
\hline \multicolumn{2}{|c|}{ Specific cardiovascular diseases } & $\mathrm{N}(\%)$ \\
\hline \multirow{4}{*}{ Congenital heart diseases $(\mathrm{N}=15)$} & Ventricular septal defect & $6(40.0)$ \\
\hline & Tetralogy of fallot & $2(13.3)$ \\
\hline & Atrial septal defect & $4(26.7)$ \\
\hline & Others & $3(20.0)$ \\
\hline \multirow{3}{*}{ Valvular heart disease $(\mathrm{N}=85)$} & Rheumatic heart disease & $60(70.6)$ \\
\hline & Degenerative heart disease & $22(25.9)$ \\
\hline & Mitral valve prolapse & $3(3.5)$ \\
\hline \multirow{4}{*}{ Cardiomyopathies $(\mathrm{N}=80)$} & Dilated cardiomyopathy & $62(77.5)$ \\
\hline & Hypertrophic cardiomyopathy & $2(2.5)$ \\
\hline & Postpartum cardiomyopathy & $9(11.3)$ \\
\hline & Alcoholic cardiomyopathy & $7(8.8)$ \\
\hline \multirow{6}{*}{ Arrhythmias $(\mathrm{N}=27)$} & Complete heart block & $14(51.9)$ \\
\hline & Atrial fibrillation & $3(11.1)$ \\
\hline & Second degree heart block & $1(3.7)$ \\
\hline & WPW & $2(7.4)$ \\
\hline & Sinus node dysfunction & $2(7.4)$ \\
\hline & Supraventricular tachycardia & $5(18.5)$ \\
\hline \multirow{2}{*}{ Veno-thromboembolism $(\mathrm{N}=11)$} & Deep vein thrombosis & $9(81.8)$ \\
\hline & Pulmonary embolism & $2(18.2)$ \\
\hline
\end{tabular}

Table 4. The number of patients by disease and age category.

\begin{tabular}{cccccccccc}
\hline \multicolumn{8}{c}{ Age categories (years) } \\
\hline CVD & $<20$ & $20-29$ & $30-39$ & $40-49$ & $50-59$ & $60-69$ & $70-79$ & $>=80$ & Total \\
\hline HHD & - & 1 & 8 & 18 & 31 & 29 & 52 & 15 & 154 \\
VHD & 18 & 11 & 6 & 11 & 10 & 8 & 14 & 7 & 85 \\
CMP & - & 6 & 15 & 9 & 17 & 13 & 18 & 2 & 80 \\
ARR & - & 4 & 2 & 2 & 4 & 8 & 6 & 1 & 27 \\
CAD & - & - & - & 1 & 7 & 4 & 6 & - & 18 \\
CHD & 5 & 2 & 4 & 2 & 1 & 1 & - & - & 15 \\
PH & - & - & 2 & 1 & 1 & 2 & 5 & - & 8 \\
VTE & - & 1 & 3 & 2 & 1 & 1 & 3 & - & 11 \\
IE & 2 & 2 & - & - & - & - & - & - & 4 \\
SCHD & 1 & 1 & 1 & 1 & - & - & - & - & 4 \\
CP & - & - & - & 1 & 1 & 1 & - & - & 3 \\
THD & - & - & - & 1 & 1 & 1 & - & - & 3 \\
PCD & - & - & - & 1 & - & - & - & 1 & 3 \\
Others & - & - & 1 & 2 & 6 & 3 & 5 & - & 17 \\
\hline
\end{tabular}

HHD = Hypertensive Heart Disease, VHD = Valvular Heart Disease, CMP = Cardiomyopathy, ARR = Arrhythmia, $\mathrm{CAD}=$ Coronary artery Disease, $\mathrm{CHD}=$ Congenital Heart Disease, $\mathrm{VTE}=$ Veno Thromboembolism, $\mathrm{PH}=$ Pulmonary Hypertension, $\mathrm{CAD}=$ Coronary artery Disease, $\mathrm{IE}=$ Infective Endocarditis, $\mathrm{SCHD}=$ Sickle Cell Heart Disease, $\mathrm{CP}=$ Cor pulmonale $\mathrm{THD}=$ Thyroid Heart Disease, $\mathrm{PCD}=$ Pericardial Diseases. 
Table 5. Associated medical conditions.

\begin{tabular}{|c|c|c|}
\hline Variables & Number & Percentage (\%) \\
\hline Hypertension & 209 & 48.4 \\
\hline Diabetes & 34 & 7.9 \\
\hline Obesity & 9 & 2.1 \\
\hline Alcohol & 7 & 1.6 \\
\hline Smoking & 5 & 1.2 \\
\hline Stroke & 5 & 1.2 \\
\hline Sickle cell disease & 5 & 1.2 \\
\hline Bronchial Asthma & 3 & 52 \\
\hline COPD & 2 & 0.5 \\
\hline Gout & 2 & 0.5 \\
\hline Glaucoma & 1 & 0.2 \\
\hline Nephrotic syndrome & 1 & 0.2 \\
\hline Stoke Adams attacks & 2 & 0.5 \\
\hline Splenomegaly & 1 & 0.2 \\
\hline Thyrotoxicosis & 3 & 0.7 \\
\hline Parkinson's disease & 2 & 0.5 \\
\hline Breast carcinoma & 1 & 0.2 \\
\hline HIV Infection & 1 & 0.2 \\
\hline Liver cirrhosis & 1 & 0.2 \\
\hline Septicaemia & 1 & 0.2 \\
\hline
\end{tabular}

Understandably, hypertension was the commonest associated medical condition noted $(\mathrm{n}=209,1.6 \%)$. Diabetes, obesity and alcohol use were seen in 34 (7.9\%), $9(2.1 \%)$ and $(\mathrm{n}=7,1.6 \%)$ subjects respectively. Other significant associated medical conditions found in this study were cerebrovascular accident and sickle cell disease seen in $5(1.2 \%)$ subjects each.

\section{Discussion}

Cardiovascular diseases pose an increasing burden on health-care system of many sub-Saharan African countries. The present study provides important update regarding trend and spectrum of cardiovascular disease morbidity, which may be helpful to health planners and policy makers in Ghana and other sub-Saharan African countries. There was a preponderance of females in this cohort (53.0\% vs. $47.0 \%)$ and this is comparable to similar studies done in Ghana [9], Cameroun [12] and Nigeria [16] [17], which also reported female predominance $(60.9 \%$ vs. $39.1 \%),(60.9 \%$ vs. $39.1 \%)$ and $(61.2 \%$ vs. $38.8 \%)$ respectively.

The female dominance might be a reflection of the fact that CVD and its risk factors such as hypertension are commoner in females than their male counterparts especially after menopause [24] [25]. Differences in the health seeking be- 
haviours of males and females might also play a role in the differences in CVD prevalence in the two sexes as females tend to be more enthusiastic in health-related issues [26].

The mean age of the CVD patients was $55.35( \pm 19.09)$ years. This is in line with what was found in previous studies in Accra, Ghana and other parts of sub-Saharan Africa [9] [12] [16] [17] [27] [28]. Compared to the Western world, CVD in sub-Saharan Africa tends to occur at a much younger age [10]. This finding could be due to the major contribution of rheumatic heart disease as a cause of CVD in sub-Saharan Africa.

In the present study, the five major cardiovascular diseases seen at the outpatient cardiac clinic in a teaching hospital in Kumasi, Ghana were hypertensive heart disease $(n=154 ; 35.6 \%)$, valvular heart disease $(n=85 ; 19.7 \%)$, cardiomyopathy $(\mathrm{n}=80 ; 18.5 \%)$, Arrhythmias $(\mathrm{n}=27 ; 6.3 \%)$ and coronary artery disease $(n=23 ; 5.3 \%)$. This observation is in line with the results of other studies done in Ghana [9], Cameroun [12] and Nigeria [16] [17]. In the study conducted in Ghana [9] more than a decade ago, the pattern of cardiovascular diseases in order of decreasing prevalence was hypertensive heart disease, rheumatic heart disease, cardiomyopathy, coronary artery disease and others. This shows that the pattern of cardiovascular diseases in Ghana has not changed significantly over the ten-year period.

Importantly, hypertensive heart disease is by far the commonest cause of CVD in this study. Several studies have consistently reported hypertensive heart disease as the most common cause of CVD [9] [12] [16] [17] [27] [28], which is in agreement with our finding. Our finding is similar to the report of a Ghanaian study [9], but the proportion in this study (35.6\%) is higher than the previous $(18.8 \%)$. The escalating increase of incidence of hypertensive heart disease over the period could be due to the increasingly high prevalence of hypertension against a background of low rates of detection, treatment and control.

The predominance of hypertensive heart disease is not surprising, given that hypertension forms the foundation and fulcrum of cardiovascular diseases in Africa, with high prevalence, poor control rates and frequent cardiac complications [18] [29] [30] [31]. In Nigeria, Saidu et al. [17] reported that 40.3\% of cardiac disorders seen at the Murtala Muhammad Specialist Hospital were due to hypertension. Amoah et al. [32], found that $21.3 \%$ of 572 heart failure cases seen at the National Cardiothoracic Centre at the Korle Bu Teaching Hospital, Accra, were due to hypertension. Owusu I.K. et al. reported that hypertension accounted for $45.0 \%$ of causes of adult heart failure in Kumasi, Ghana [19]. These findings point out the burden and impact of hypertension in Ghana. In fact, hypertension in Ghana remains under-diagnosed and undertreated, frequently leading to hypertensive heart disease, chronic heart failure, renal failure and cerebrovascular disease [18] [19] [33].

Indeed, hypertension is one of the most studied cardiovascular risk factors in sub-Saharan Africa. The upsurge of hypertension in sub-Saharan Africa is due to continuing socioeconomic advancement, progressive urbanization and a shift 
towards western habits such as high smoking rates, unhealthy diets and a more sedentary lifestyle as well as ageing of the population [1]. This finding is quite alarming and as such measures aimed at prevention, early detection and control of hypertension should be more aggressively pursued.

The various forms of valvular heart disease constituted the second most frequent cause of cardiovascular disease in this study with prevalence of $19.7 \%$. This finding compares well with similar studies done in sub-Saharan African, which showed a significant contribution of valvular heart disease [11] [12] [19]. Rheumatic heart disease was the most preponderant valvular heart disease, accounting for $70.6 \%$ of cases in our study, a finding similarly reported in Ghana and other sub-Saharan Africa settings [9] [13] [19] [27] [34]. Rheumatic heart disease remains a major cause of cardiovascular disease in Ghana, with mitral valve lesion as the most common rheumatic valvular heart disease [9].

Rheumatic heart disease results from repeated acute rheumatic fever attacks following exposure to Group A streptococci (GAS) throat infections. Despite the decline in the incidence in rheumatic heart disease in developed countries [9] [14] [34] [35], Sub-Saharan African countries continue to record relatively high levels of the disease, where they are associated with poor prognosis resulting from delayed diagnosis and treatment [9] [11] [14] [19] [34] [35]. The prevalent poverty with associated poor environmental sanitation, overcrowding, lack of personal hygiene, malnutrition and shortage of healthcare resources in our region of the world are said to underscore the relatively high rates of acute rheumatic fever (ARF) and rheumatic heart disease [9] [36]. This report highlights the crucial need of early detection and widespread treatment of throat infections with appropriate antibiotics in our setting.

Cardiomyopathy of varying etiology accounted for the third commonest cause of cardiovascular disease in this study (18.5\%). Similar findings were noted from previous studies done in Ghana and some other African countries [9] [13] [16] [17] [19]. In line with this finding, Habte et al. [13], noted that $20.2 \%$ of 783 cardiac patients at the cardiac follow-up clinic of Jimma University Specialized Hospital. South West Ethiopia had cardiomyopathy. This result is also in agreement with a study in Malawi by Soliman et al. [34]; they found the prevalence of cardiomyopathy to be $9.8 \%$. In a study of 708 cardiac patients at the National Cardiothoracic Centre at the Korle Bu Teaching Hospital, Accra, Amoah et al. [9] reported a comparable proportion of cases with cardiomyopathy (14.6\%). Owusu et al. reported that cardiomyopathy accounted for $15.0 \%$ of causes of adult heart failure in Kumasi, Ghana [19]. Dilated cardiomyopathy was the most frequent cardiomyopathy, accounting for $78.6 \%$ of cases in our study. This predominance was reported elsewhere [9] [13] [19] [27]. In facts, it is well documented that cardiomyopathy remains a significant cause of chronic heart failure in Ghana and other sub-Sahara African countries [18] [19] [33]. These findings therefore suggest the need to carry out studies and update findings on the epidemiology, clinical characteristics and outcomes of patients with cardiomyopa- 
thy.

Arrhythmia was the fourth leading cause of cardiovascular disease accounting for $6.3 \%$ of the study patients. This finding is among the highest in the series of published data on spectrum of CVD across the various centres [9] [13] [34]. Our finding is comparable to similar studies done in Northern Malawi [34] and South West Ethiopia [13] which reported prevalence of $4.0 \%$ and $3.5 \%$ respectively in patients with cardiovascular diseases but understandably higher compared to the finding of $1.4 \%$ at the National Cardiothoracic Centre, Korle Bu Teaching Hospital, Accra, Ghana [9]. Difference in the methodology may have contributed to the different prevalence rates.

Complete heart block (51.9\%) was the most common cardiac arrhythmia identified in this study. This observation is in line with the finding of Amoah et al. [9], who noted that among cardiac patients with structurally normal hearts on echocardiography, complete heart block was the commonest arrhythmia. However, in South Africa, Mbewu et al. [3] reported that, atrial fibrillation is the most common cardiac arrhythmia with incidence of about 8 percent of the population 70 years and older. In a cardiac clinic in Soweto, South Africa, Sliwa et al. [37] reported that $33 \%$ of patients had some form of arrhythmia; and $7 \%$ had atrial fibrillation.

Coronary artery disease was found to be the fifth leading cause of cardiovascular disease in this study with prevalence of $4.2 \%$, comparable to the $2.4 \%$ found in a Cameroonian study [12]. It was also close to the finding of $6.6 \%$ by Talle et al. in a study involving 1224 cardiovascular disease patients diagnosed using transthoracic echocardiography in Nigeria [16]. The finding of this study, however, differed considerably from what was previously reported by Amoah et al. [9]; they found $11.3 \%$ of 708 cardiac patients referred to the National Cardiothoracic Centre, Korle Bu Teaching Hospital, Accra, Ghana had coronary artery disease. Of note, in a similar study in Ethiopia, coronary artery disease was ranked fourth among CVD with a prevalence of $12.0 \%$ [13]. The disparity could be partly due to difference in case definition, sample size and the population studied. The major risk factors for coronary artery disease identified in our cardiac patients were hypertension, diabetes mellitus and obesity; which compares well with previous studies done in Ghana [9] and some other African countries [34].

Despite the reported rising incidence of coronary artery disease in sub-Saharan African over the years [9] [13] [16] [38], our finding suggests that coronary artery disease is still a relatively modest contributor of CVD in sub-Saharan Africa. Although we found a relatively low prevalence in this cohort, a progressively increasing trend in incidence of coronary artery disease is now being seen in sub-Saharan Africa, particularly in urban areas [9] [13] [16]. Undoubtedly, the gradual rising burden of coronary artery disease is mainly driven by the prolonged exposure to high levels of CVD risk factors and population aging as well as the increasing of diagnosis of coronary artery disease as a result of widespread 
use of more sensitive diagnostic techniques. Further research is however needed to ascertain the actual prevalence and the trend of coronary artery disease; and to confirm the level and distribution of risk factors in Ghanaian population.

In the present study, congenital heart disease accounted for only $3.5 \%$ of our study subjects. The low prevalence of congenital heart disease reported is also similar to what was noted from previous reports from other centres in Cameroon [12] and Malawi [34] with the findings of $2.3 \%$ and $4.0 \%$ respectively. It was also close to the $1.8 \%$ found by Ogah et al. among 1441 cardiac patients referred for echocardiography in Nigeria [27]. In particular, a more recent study evaluating the echocardiographic pattern of cardiac diseases involving 1012 subjects in a North Western Nigerian tertiary health institution found a significantly low prevalence $(0.3 \%)$ as congenital heart disease [17]. In a recent study at our teaching hospital, congenital heart disease was responsible for $1.7 \%$ of heart failure cases at the outpatient cardiac clinic [19].

On the contrary, in a study of 708 cardiac patients at the National Cardiothoracic Centre at the Korle Bu Teaching Hospital, Accra, Amoah et al. [9] reported a significant contribution of CHD (12.7\%) as a cause of CVD. This difference could be explained by the fact that mainly adults were included in the present study. This may also reflect the fact that there is an active cardiac surgical unit in that centre, there by attracting referrals of patients with congenital heart disease. The spectrum of congenital heart disease in this study is similar to earlier finding in the country with VSD being the commonest lesion [9].

In the present study, venous thromboembolism, pulmonary hypertension and infective endocarditis were diagnosed in $2.5 \%, 1.9 \%$ and $0.9 \%$ respectively. The other CVD patterns included pericardial disease, thyroid heart disease and cor-pulmonle, each representing $0.7 \%$ of the study patients. It is worth noting that, pericardial disease was relatively uncommon in the present study compared to report from earlier Ghanaian study, which found 38\% of 708 cardiac patients at the National Cardiothoracic Centre, Korle Bu Teaching Hospital, Accra, had pericardial disease [9]. This difference could be partly due to the cardiac surgical unit in the centre; there by receiving disproportionately larger number of referrals of patients with pericardial disorders that may require surgery.

\section{Conclusion}

The findings of this study support other studies that cardiovascular disease, which was once rare, is now highly prevalent in sub-Saharan Africa. Our study shows that hypertensive heart disease is the leading cause of cardiovascular disease in our setting emphasizing the need for strategies for prevention, early detection and control of systemic arterial hypertension in order to prevent, reduce or delay its grave complications. Valvular heart disease particularly rheumatic heart disease is still a major cardiac problem in Ghana, highlighting the need for improvement in housing and environmental sanitation as well early detection and treatment of streptococcal throat infections. 


\section{Acknowledgements}

The authors would like to express their sincere gratitude to the patients who participated in the study and the staff at the outpatient unit of the Directorate of Medicine, Komfo Anokye Teaching Hospital, Kumasi, Ghana for their support. Without their co-operation this study would not have been successful.

\section{Conflict of Interest}

The authors confirm that this article content has no conflict of interest.

\section{References}

[1] Gaziano, J.M. (2005) Global Burden of Cardiovascular Disease. 7th Edition, Phila Elsevier Saunders, 423-455.

[2] WHO (2017) Global Health Observatory (GHO) Data. http://www.who.int/gho/en/

[3] Mbewu, A. (2009) The Burden of Cardiovascular Disease in Sub-Saharan Africa: Burden of Cardiovascular Disease. SA Heart, 6, 4-10.

[4] Afro, W. (2005) Cardiovascular Diseases in the African Region: Current Situation and Perspectives.

[5] WHO (2004) The Global Burden of Disease: Update. http://www.who.int/healthinfo/global_burden_disease/2004_report_update/en/

[6] Lopez, A.D., Mathers, C.D., Ezzati, M., Jamison, D.T. and Murray, C.J. (2006) Global and Regional Burden of Disease and Risk Factors, 2001: Systematic Analysis of Population Health Data. The Lancet, 367, 1747-1757. https://doi.org/10.1016/S0140-6736(06)68770-9

[7] Reddy, K.S. and Yusuf, S. (1998) Emerging Epidemic of Cardiovascular Disease in Developing Countries. Circulation, 97, 596-601.

[8] Mocumbi, A.O. (2012) Lack of Focus on Cardiovascular Disease in Sub-Saharan Africa. Cardiovascular Diagnosis and Therapy, 2, 74-77.

[9] Amoah, A.G.B. (2000) Spectrum of Cardiovascular Disorders in a National Referral Centre, Ghana. East African Medical Journal, 77, No. 12. http://www.ajol.info/index.php/eamj/article/view/46763

[10] Mbewu, A. and Mbanya, J.-C. (2006) Cardiovascular Disease. In: Jamison, D.T., Feachem, R.G., Makgoba, M.W., Bos, E.R., Baingana, F.K., Hofman, K.J., et al., Editors, Disease and Mortality in Sub-Saharan Africa, 2nd Ed., World Bank, Washington DC. http://www.ncbi.nlm.nih.gov/books/NBK2294/

[11] Abdissa, S.G., Oli, K., Feleke, Y., Goshu, D.Y., Begna, D.M. and Tafese, A. (2014) Spectrum of Cardiovascular Diseases among Ethiopian Patients at Tikur Anbessa Specialized University Teaching Hospital, Addis Ababa. Ethiopian Medical Journal, 52, 9-17.

[12] Jingi, A.M., Noubiap, J.J.N., Kamdem, P., Yonta, E.W., Temfack, E., Kouam, C.K., et al. (2013) The Spectrum of Cardiac Disease in the West Region of Cameroon: A Hospital-Based Cross-Sectional Study. International Archives of Medicine, 6, 44. https://doi.org/10.1186/1755-7682-6-44

[13] Habte, B., Alemseged, F. and Tesfaye, D. (2017) The Pattern of Cardiac Diseases at the Cardiac Clinic of Jimma University Specialised Hospital, South West Ethiopia. Ethiopian Journal of Health Sciences, 20.

http://www.ajol.info/index.php/ejhs/article/view/69435 
[14] Suliman, A.A. (2009) The State of Heart Disease in Sudan: Abstract. Cardiovascular Journal of Africa, 8.

[15] Damasceno, A., Mayosi, B.M., Sani, M., Ogah, O.S., Mondo, C., Ojji, D., et al. (2012) The Causes, Treatment, and Outcome of Acute Heart Failure in 1006 Africans from 9 Countries: Results of the Sub-Saharan Africa Survey of Heart Failure. Archives of Internal Medicine, 172, 1386-1394.

[16] Talle, M.A., Anjorin, C.O., Buba, F. and Bakki, B. (2016) Spectrum of Cardiovascular Diseases Diagnosed using Transthoracic Echocardiography: Perspectives from a Tertiary Hospital in North-Eastern Nigeria. Nigerian Journal of Cardiology, 13, 39-45.

[17] Saidu, H., Sani, M.U., Mijinyawa, M.S. and Yakasai, A.M. (2015) Echocardiographic Pattern of Heart Diseases in a North-Western Nigerian Tertiary Health Institution. Nigerian Journal of Basic and Clinical Sciences, 12, 39-44.

[18] Owusu, I.K. and Acheamfuor-Akowuah, E. (2016) Prevalence and Correlates of Electrocardiographic Left Ventricular Hypertrophy in Hypertensive Patients at a Specialist Clinic in Techiman, Ghana. IOSR Journal of Dental and Medical Sciences, 1, 100-109.

[19] Owusu, I.K. and Boakye, Y.A. (2013) Prevalence and Aetiology of Heart Failure in Patients Seen at a Teaching Hospital in Ghana. Journal of Cardiovascular Diseases \& Diagnosis, 1, 131. https://doi.org/10.4172/2329-9517.1000131

[20] Whitworth, J.A. (2003) World Health Organization (WHO)/International Society of Hypertension (ISH) Statement on Management of Hypertension. Journal of Hypertension, 21, 1983-1992. https://doi.org/10.1097/00004872-200311000-00002

[21] Reményi, B., Wilson, N., Steer, A., Ferreira, B., Kado, J., Kumar, K., et al. (2012) World Heart Federation Criteria for Echocardiographic Diagnosis of Rheumatic Heart Disease-An Evidence-Based Guideline. Nature Reviews Cardiology, 9, 297-309.

[22] Jaffe, C.C. and Weltin, G. (1992) Echocardiography of the Right Side of the Heart. Cardiology Clinics, 10, 41-57.

[23] (1984) Cardiomyopathies. Report of a WHO Expert Committee. World Health Organization Technical Report Series, 697, 7-64.

[24] Reckelhoff, J.F. (2001) Gender Differences in the Regulation of Blood Pressure. Hypertension, 37, 1199-1208. https://doi.org/10.1161/01.HYP.37.5.1199

[25] Burt, V.L., Whelton, P., Roccella, E.J., Brown, C., Cutler, J.A., Higgins, M., et al. (1995) Prevalence of Hypertension in the US Adult Population. Results from the Third National Health and Nutrition Examination Survey, 1988-1991. Hypertension, 25, 305-313. https://doi.org/10.1161/01.HYP.25.3.305

[26] Achieng, L., Joshi, M.D., Ogola, E.N. and Karari, E. (2009) Adequacy of Blood Pressure Control and Level of Adherence with Antihypertensive Therapy. East African Medical Journal, 86, 499-506.

[27] Ogah, O.S., Adegbite, G.D., Akinyemi, R.O., Adesina, J.O., Alabi, A.A., Udofia, O.I., et al. (2008) Spectrum of Heart Diseases in a New Cardiac Service in Nigeria: An Echocardiographic Study of 1441 Subjects in Abeokuta. BMC Research Notes, 1, 98. https://doi.org/10.1186/1756-0500-1-98

[28] Uwanuruochi (2017) Initial Experience with Echocardiography at the Federal Medical Centre, Umuahia, Nigeria. Nigerian Journal of Cardiology, 12, 13-17.

http://www.nigjcardiol.org/article.asp?issn=0189-7969; year $=2015$; volume $=12 ;$ issue $=$ 1 ;spage $=13$; epage $=17$; aulast $=$ Uwanuruochi

[29] Kengne, A.P., Awah, P.K., Fezeu, L. and Mbanya, J.C. (2007) The Burden of High 
Blood Pressure and Related Risk Factors in Urban Sub-Saharan Africa: Evidences from Douala in Cameroon. African Health Sciences, 7, 38-44. http://www.ajol.info/index.php/ahs/article/view/6989

[30] Bosu, W.K. (2010) Epidemic of Hypertension in Ghana: A Systematic Review. BMC Public Health, 14, 418.

[31] Addo, J., Smeeth, L. and Leon, D.A. (2009) Hypertensive Target Organ Damage in Ghanaian Civil Servants with Hypertension. PLoS ONE, 4, e6672. https://doi.org/10.1371/journal.pone.0006672

[32] Amoah, A.G.B. and Kallen, C. (2000) Aetiology of Heart Failure as Seen from a National Cardiac Referral Centre in Africa. Cardiology, 93, 11-18. https://doi.org/10.1159/000006996

[33] Addo, J., Agyemang, C., Smeeth, L., de-Graft, A.A., Edusei, A.K. and Ogedegbe, O. (2012) A Review of Population-Based Studies on Hypertension in Ghana. Ghana Medical Journal, 46, 4-11.

[34] Soliman, E.Z. and Juma, H. (2008) Cardiac Disease Patterns in Northern Malawi: Epidemiologic Transition Perspective. Journal of Epidemiology, 18, 204-208.

[35] Zühlke, L., Mirabel, M. and Marijon, E. (2013) Congenital Heart Disease and Rheumatic Heart Disease in Africa: Recent Advances and Current Priorities. Heart, 99, 1554-1561. https://doi.org/10.1136/heartjnl-2013-303896

[36] Sani, M.U., Karaye, K.M. and Borodo, M.M. (2007) Prevalence and Pattern of Rheumatic Heart Disease in the Nigerian Savannah: An Echocardiographic Study. Cardiovascular Journal of Africa, 18, 295-299.

[37] Sliwa, K., Wilkinson, D., Hansen, C., Ntyintyane, L., Tibazarwa, K., Becker, A., et al. (2008) Spectrum of Heart Disease and Risk Factors in a Black Urban Population in South Africa (the Heart of Soweto Study): A Cohort Study. The Lancet, 371, 915-922. https://doi.org/10.1016/S0140-6736(08)60417-1

[38] Akinboboye, O., Idris, O., Akinboboye, O. and Akinkugbe, O. (2003) Trends in Coronary Artery Disease and Associated Risk Factors in Sub-Saharan Africans. Journal of Human Hypertension, 17, 381-387. https://doi.org/10.1038/sj.jhh.1001562 